\title{
COMBINING VETERANS AND TEACHERS IN A UNIQUE SERVICE LEARNING EXPERIENCE
}

\author{
Mahender Mandala \\ Doctoral Student, Department of Rehabilitation \\ Science \& Technology \\ University of Pittsburgh \\ Pittsburgh, PA 15232 \\ mam447@pitt.edu
}

\author{
Mary Goldberg \\ Asst. Professor, Department of Rehabilitation \\ Science \& Technology \\ University of Pittsburgh \\ Pittsburgh, PA 15232 \\ mrh35@pitt.edu
}

\author{
Jonathan Pearlman \\ Asst. Professor, Department of Rehabilitation Science \& Technology \\ University of Pittsburgh \\ Pittsburgh, PA 15232 \\ jlp46@pitt.edu
}

Abstract - This paper describes the design-based service learning model utilized to provide an engaging STEM experience to local K-12 science and math teachers and U.S. military veterans returning from service and transitioning to secondary education. A critical factor that can contribute to increased student outcomes from a service-learning program is the level of preparation a teacher has as a mediator of knowledge and an active partner. Professional development activities directed towards in-service teachers could potentially alleviate this issue. Furthermore, such activities, when combined with well-developed inquiry-based learning pedagogy, could provide for increased engagement and understanding of STEM of students. Recent evidence shows that veterans may be more likely than the general population to be interested and well suited for a career in engineering. With more than two million veterans returning from service in the near future, the shortage in undergraduate engineering enrollment could be assuaged. The REVT format at Pitt has the potential to provide veterans with the support to experience STEM without the fear of failure, while allowing teachers to benefit from the field experience and leadership skills of veterans in the program. The juxtaposition of these two populations allows for co-mentoring opportunities, with each group benefiting from contrasting experiences.

Index Terms - design learning, K-12 teachers, professional development, veterans

\section{INTRODUCTION}

At the K-12 grade levels, service learning has been shown to increase a student's personal and social development, civic responsibility, academic learning, career exploration and aspirations. ${ }^{1}$ Furthermore, research suggests that service learning increases the mutual respect between teachers and students, and builds more cohesive and positive relationships between peers. ${ }^{2,3}$ Not surprisingly, the popularity of service learning has been on the rise with better outcomes associated with programs that thoroughly integrate service and academic learning. ${ }^{1,4}$ 
A critical factor that can contribute to increased student outcomes from a service-learning program is the level of preparation a teacher has as a mediator of knowledge and an active partner. ${ }^{1}$ Professional development activities directed towards in-service teachers could potentially alleviate this issue. The National Science Foundation funds several professional development activities centered on science, technology, engineering and math (STEM) for inservice K-12 teachers under the visage of Research Experience for Teachers (RET).

Pitt is one of the many RET centers, and has developed a unique model for professional development training that utilizes a collaborative design-based service learning (DBSL) pedagogy with a specific focus on K-12 teachers and veterans. The DBSL pedagogy employed at University of Pittsburgh is related to products that improve the lives of people with disabilities (PWD) who often face social discrimination on top of the intrinsic limitations as a result of their disability.

Creating an inclusive environment for PWD requires both social acceptance and removal of any barriers that prevent full participation. Some of the personal barriers are remedied through the use of Assistive Technology (AT). AT plays a critical role in the lives of PWD; it provides increased opportunities to education, employment, and independence. ${ }^{5-9}$ However, the cost associated with acquiring AT can be prohibitive for low-income and uninsured families, further impacting these individuals and families. There is a real need for high-quality and low-cost AT that is contextually appropriate for use by PWD across socioeconomic environments. This is a real world engineering, design and humanities problem which requires creative and empathetic thinking. Design and project-based courses that engage students and faculty from both technical and health science disciplines enable the development of useful AT. ${ }^{10}$ In addition to this tangible benefit, DBSL that focuses on the disability community encompasses the need for increased awareness of the community as well as affect STEAM (Science, Technology, Engineering, Arts and Math) learning of its participant.

In this paper, we provide a description of the background and motivation for our Research Experience for Veterans and Teachers (REVT), an overview of our approach, and the work-in progress evaluation and recommendations for replicability and scalability of this program. We posit that DBSL has the potential to increase student academic outcomes and this scalability could help bring the benefits to a wider population more quickly. Our approach at DBSL allows for integrating curricular subject matter using scaffolded and well developed activities that allow students to utilize thinking skills such as analysis, evaluation and problem solving - ingredients for an effective service learning program.

\section{BACKGROUND}

\section{The RET Program}

In the year 2001, the National Science Foundation (NSF) initiated the RET program with a stated goal to "help build long-term collaborative partnerships between K-14 science, technology, engineering, and mathematics (STEM) teachers and the NSF research community by involving the teachers in engineering-funded research and then helping them translate their research experiences into classroom activities". "The program has since become quite popular, with currently around $\$ 91 \mathrm{M}$ invested in more than 60 active RET programs across 25 U.S. states. ${ }^{12}$ There is a wide-ranging difference in how the program is facilitated between institutions with 


\section{International Journal for Service Learning in Engineering Special Edition, pp. 381-405, Fall 2014 \\ ISSN 1555-9033}

varying degree of teacher participation, researcher involvement, and duration of training and intended goals. ${ }^{13}$ In addition to the RET program, there are several such teacher-focused professional development programs funded by state, local as well as private foundations. ${ }^{14}$ Although marked by their diversity in approach, these teacher-focused experiential programs are unified by their fundamental underlying philosophy which is entrenched in the theories of constructivism, scaffolding and apprenticeship.

An early evaluation of the RET program revealed that teachers were satisfied with their experience in the program and reported greater personal and professional benefit, ${ }^{11}$ and that there were significant positive outcomes from the perspective of the participants. ${ }^{13,15}$

The current RET programs last anywhere from one to ten weeks, usually over the summer, for in-service teachers. ${ }^{12}$ Some focus solely on providing teachers an opportunity to work with scientists in laboratories, while others follow a more structured pedagogical approach with research and project based course work. ${ }^{11,13}$ Additionally there are hybrid programs that focus on both providing a research experience as well as guidance on implementing such experiences into the teacher's own classrooms through an additional curriculum development component. The RET-funded program at the University of Pittsburgh is a hybrid teacher/research experience program. The program differentiates itself from its peers by its inclusion of both teachers and returning U.S. military veterans in the training, the length of training, and the use of a client as part of the team.

\section{The need for professional development: K-12 Teachers}

The National Science Board has expressed concern with the current state of affairs in K-12 education specifically with 'the growing inequality of K-12 students' access to a solid math and science education". ${ }^{16}$ The students exiting the K-12 schools are often under-prepared for a career in STEM and require remedial courses to begin post-secondary education. ${ }^{17}$ Additionally, there is evidence that suggests that the attitude students have towards STEM education and careers, along with STEM course experience and preparation at the high school level, play an important role in major choice and attrition rate. ${ }^{18-20}$ Therefore, engaging and relevant approaches that encourage K-12 students to understand and increase conceptual knowledge should be developed. Inquiry-based instruction has the potential to lead students to a more engaged science and math experience and therefore is a valuable tool. ${ }^{21,22}$ Furthermore, inquiry-based instruction provides a basis for understanding the nature of scientific knowledge and the nature of inquiry itself. ${ }^{23}$

This need for engagement is not just limited to students, K-12 teachers face high levels of emotional exhaustion and burnout. ${ }^{24,25}$ One of the reasons of this stress on teachers comes from the feeling of not being connected with their students, reduced personal outcome and cynicism of student motives and outcomes. ${ }^{25,}{ }^{26}$ Based on our experience, providing teachers with DBSL experiences enhance their overview of teaching, provides the motivation and confidence to engage their students in more realistic, relevant problem spaces, and subsequently have a new perspective on what defines a successful student. Also, combining inquiry-based instruction with a service learning component (e.g., working with a real client) could enhance a student's academic experience; ensure the achievement of curricular goals; and teach a student how to be a contributing member of her community. ${ }^{27}$

Yet, most science and math teachers have little experience and understanding of inquiry as a

scientific instrument, hindering its implementation as successful pedagogical tool. ${ }^{28-32}$ The 


\section{International Journal for Service Learning in Engineering Special Edition, pp. 381-405, Fall 2014 \\ ISSN 1555-9033}

burden of developing an inquiry-based course without the necessary experience or foundation could be alleviated by focused teacher professional development sessions, workshops or internships. One such avenue could be the Research Experience for Teachers program.

\section{The need for assisted transition to academia: U.S. Military Veterans}

Most often, veterans returning to student life require an adjustment period that includes time to relearn study skills, reacquaint themselves with a new social environment and changing relationships, and adapt to more autogenic routines. ${ }^{33-35}$ Furthermore, a subset of this special student population includes veterans who have acquired disabilities through trauma, forcing a sudden dramatic shift in lifestyle that could require an extended adjustment period.

Recent evidence shows that veterans may be more likely than the general population to be interested and well suited for a career in engineering. While $6 \%$ of standard SAT takers cite an interest in engineering, ${ }^{36}$ military assessments suggest upwards of $35 \%$ service members may be interested in engineering because of positions they have held while serving. ${ }^{37}$ With an estimated two million persons with military experience returning to post-secondary institutions in the near future, ${ }^{38}$ the science and engineering workforce could receive an important boost. By providing the necessary guidance and STEM experience, more veterans could be recruited into the engineering and science fields, entering with strong self-efficacy and interest in the field.

Veterans are an important minority within our culture. They have unique leadership experiences, global perspective on issues and have made sacrifices to safeguard the ideals of the United States, and consequently represent a potential campus resource for civilian students and academics alike to gain from their insights and experiences.

\section{Inclusion of veterans in RET: Birth of REVT}

Programs similar to the professional development activities targeted at teachers, mentioned above, have the potential to provide an equally enriching and engaging STEM experience for the veterans. The two populations, teachers and veterans, have very similar needs albeit with different goals. The teachers intend to gain real world STEM experience and a better understanding of both technology and pedagogical treatment of STEM content, while the veterans want to test the waters of engineering degree programs and careers without the fear of failure.

This opportunity to create a new learning environment that could have potential benefits to both teachers and veterans provided the impetus to develop the REVT program. The program is supported by NSF's Veterans Research Supplement (VRS) devised with the aim of engaging veterans in STEM fields. ${ }^{39}$ VRS funds are available to current active NSF awardees to augment veterans into their programs.

\section{The RET program at the University of Pittsburgh}

The RET program at Pitt began in the 2005 with the goal of increasing STEM engagement and achievement by providing research and product development experiences to middle and high school STEM teachers. The program followed a two-part hybrid approach, with a design based learning unit focusing on providing an authentic product development experience for the teachers 
through lectures and working on a real life project, and a curriculum development unit that helped teachers convert their experiences into an implementation for their respective STEM classrooms. Over 50 teachers have participated in the program over 9 years and the overall assessment of the program was overwhelmingly positive, with increased teacher understanding of STEM content and changes in their pedagogical approaches. ${ }^{40}$ The current iteration of the program, REVT, is led by Pitt's Department of Rehabilitation Science and Technology and the Learning Research and Development Center.

The REVT format at Pitt has the potential to provide a classroom-centered experience that includes typical classwork, homework and social structure; thereby providing a more realistic experience to what the veterans could potentially face in their short term future. On the other end, teachers could benefit from the field experience and leadership skills of veterans in the program. The juxtaposition of these two populations allows for co-mentoring opportunities, with each group benefiting from contrasting experiences. For example, it was noted in the program that veterans often were quick to learn the software used in the class and provided assistance to the teachers, while the teachers were able to mentor the veterans on the use of math and science in problem solving.

\section{Program OVerview}

The program is hosted at the Human Engineering Research Laboratories (HERL) part of Pitt's Department of Rehabilitation Science and Technology. The mission of HERL is to continuously improve the mobility and function of people with disabilities through advanced engineering in clinical research and medical rehabilitation. As such, service learning opportunities are inherent in the labs' research efforts. People with disabilities are well integrated into the lab, as part of the design teams, research teams or as participating clients. HERL houses research groups focusing on a range of subjects from Biomechanics to Medical Robotics and Assistive Technology, in addition to a fully equipped prototyping and fabrication facility and an AT test lab.

All REVT participants have full access to these resources as part of their experiential learning. The ability to quickly prototype ideas is a quintessential need of any design course and REVT participants are allowed access to prototyping tools ranging from the basic crafts to advanced desktop 3D printing. The participants include local K-12 school teachers, usually in pairs of math and science teachers, and local veterans returning from military school and transitioning to post-secondary education.

The REVT is split into four phases in the following chronological order:

1. A DBSL course for both veterans and teachers (12 weeks, spring).

2. A curriculum development workshop for teachers (4 weeks, summer) and Mentored research experience for Veterans (10 weeks, summer).

3. Implementation of the DBSL unit in K-12 schools of participating teachers (at least an 8 week module, fall). Veterans receive continued guidance and support as they transition to their academic goals.

4. A design competition for K-12 students from the participating schools.

In the following sections we will take a look at each of these components in detail. 
This 12-week class focuses on providing teachers and veterans with an authentic engineering design and service learning experience, while working on a real life project. The class itself follows a flipped instruction approach, with class time dedicated to experiential learning through homework and project discussion, prototype development, as well as any training on the technology used in class when needed. The class work aligns with the engineering design process as detailed by Ulrich and Eppinger in their book, Product Design and Development. This also forms the textbook for the class and is provided to each participant. Pre-recorded lectures and assignments are provided in advance, with majority of the class related work being carried out over Google services including Drive, Hangout and Documents (Figure 1, shows an example screen grab of the Google services utilized for the class; showing google drive folder structure and video tutorial on YouTube).

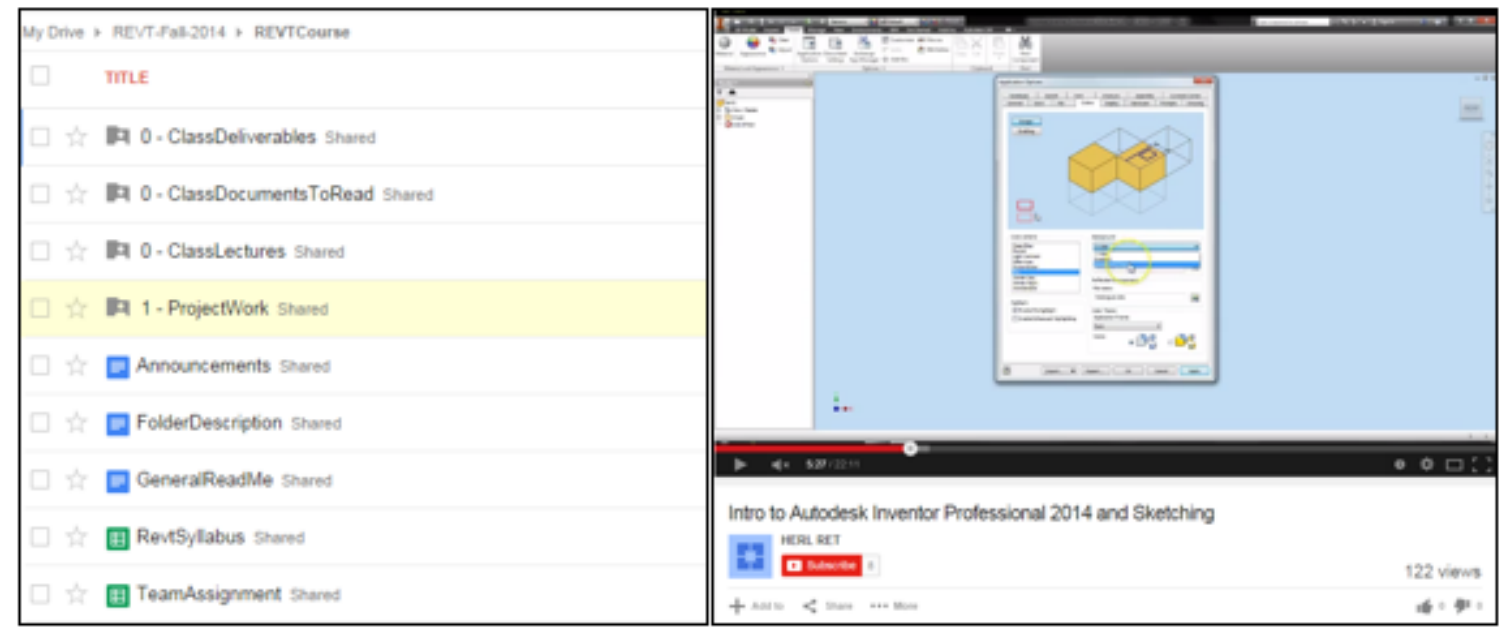

FIGURE 1

(LEFT) SCREEN GRAB SHOWING THE FOLDER ORGANIZATION FOR THE CLASS. (RIGHT) SCREEN GRAB SHOWING THE TRAINING TOOLS FOR AUTODESK INVENTOR USED FOR THE CLASS. THE TOOLS ARE AVAILABLE AT: http://goo.gl/mjkppn

Additionally, when the clients are introduced, they are integrated into the team and work alongside the participants on the project (however, the clients are instructed not to lead). The clients selected for the course are typically people with disabilities (PWD) requiring an assistive technology device. The clients are often identified from the graduate student population of the school, and/or through the recommendations of the Center for Assistive Technology (CAT) at the University of Pittsburgh Medical Center and the instructors of the course. The identified clients are provided with a prospectus of the course, and detailed information on their time commitments and expectations for the program. The close integration of the clients in the teams, allows the clients to often also mentor the teams, increasing the collaboration and communication between the two, while creating opportunities for cross-learning. This mentoring usually takes the form of inculcating disability etiquette and understanding of the disability world into the minds of team members, providing insights on working with PWDs, and in some cases where the clients have experience with design (most clients identified for the program so 
far have been lead users, who have developed home-grown solutions to their assistive technology needs) the mentoring also includes technical aspects of product design for PWD including the human-centered approaches. Such interaction has the potential to increase the appropriateness of the design, and has been shown to benefit service outcomes. ${ }^{41}$ For their participation, the clients were provided an honorarium.

The class meets once per week in person for a three hour session with assigned pre-readings and lectures. The coursework, individual assignment and textbook readings are front loaded (typically completed within the first half of the 12-week class) with the pace of this instruction determined through live feedback collected from participants. This feedback is collected through an online journal that the participants are encouraged to maintain and viewed by the instructors of the class. The quotes below are examples of kind of feedback we see in the journals:

"I think the hands on activities really make you understand an engineer design process quickly. Taking apart the appliance and figuring out user needs was great backwards design set up."

"The biggest challenge this week was balancing the workload of reading/[home]work/collaboration/revision ... I hope that we have 1 or 2 more Autodesk [CAD software] projects since we will need to be very proficient in Autodesk going forward."

"I am looking forward to having a design concept or concepts that we can prototype, test, and redesign."

Another intention of front loading the class is to provide an opportunity for the participants to reflect on the design tools that the students encounter (ethnographic, brainstorming, sketching and other similar tools) with the potential of revisiting the material as they approach the project work and begin applying some of the knowledge learned, providing another learning benefit. And although there is frequent scaffolding of project management, providing the participants with all tools and understanding of the process beforehand allows them time to reflect and determine their utility on their own. Having lectures pre-recorded also allows those who experience difficulties to consult previous materials and revise as they apply those tools or principles in their projects. In some cases, this material can be directly utilized by the teachers in their classrooms thereby reducing the burden of developing it themselves. DBSL is a time intensive process and approaches such as flipped classroom allow for an efficient use of the participants time.

There is continuous professional development that provides opportunities to both populations to acquire and improve their technical skills and gain a deeper understanding of the disability community throughout the program (figure 2, showcases a typical client-participant interaction and class activities designed to help participants familiarize with good/bad designs). This deep understanding is particularly useful for teachers who could use this experience to inform their interaction with students with disabilities in inclusive classrooms - an issue currently facing the mainstreaming programs. . $^{42,43}$

The participants are provided training on computer-aided design tool - Autodesk Inventor, best practices of using online collaboration tools including video conferencing and collaborative 
documentation, use of desktop 3D printing (Makerbot Replicator 2X) including best practices and maintenance, workshops on fabrication, hand tools, machine shop nomenclature, and demos and tours of fabrication facilities. This training is especially important for teachers who act as facilitators in their students' attempts to make sense of science and design and its relation to the big-picture. Thus understanding how design works from start to finish, including various fabrication technologies, allows the teachers to share this knowledge with their students, providing real life examples that inform and assist their learning.

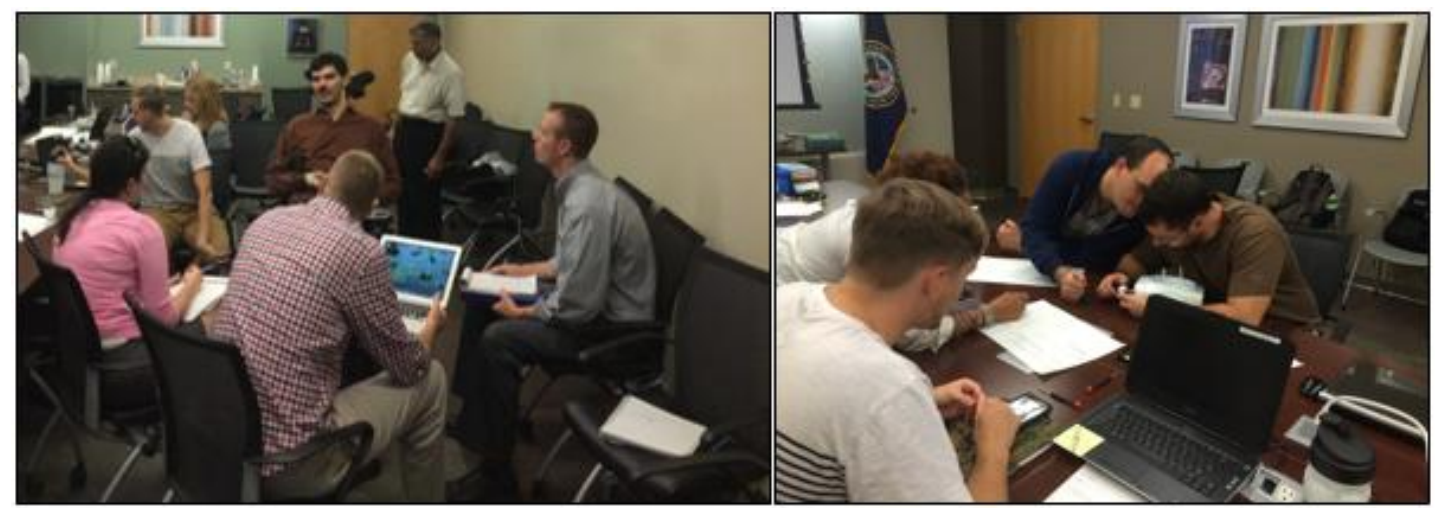

FIGURE 2

(LEFT) A TEAM INTERACTING WITH THEIR CLIENT. (RIGHT) REVERSE ENGINEERING A COOKING STOVE

The projects utilized in this course are focused on quality of life technology. Using AT projects provides a motivational factor, especially for the novice product design students that might be missing in projects that traditionally focus on the artifacts of design itself rather than the benefits to humankind. It also allows these first time designers to better understand humancentered design and design empathy working with a real individual with the potential of seeing a direct impact of their work. This aspect of service learning has the potential to increase the selfesteem and confidence of the participants, and provide a sense of accomplishment. 


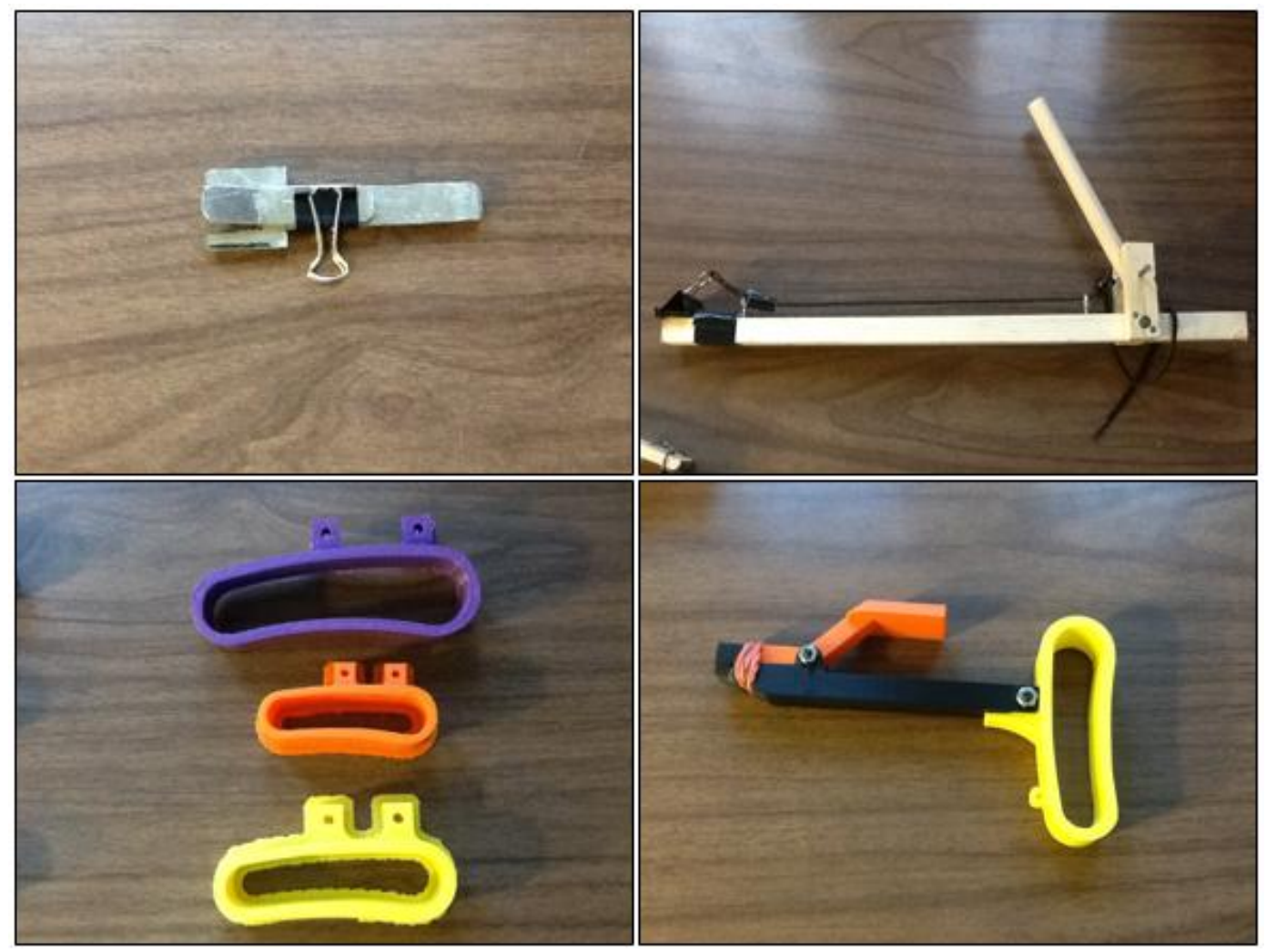

FIGURE 3

IMAGES SHOW THE PROGRESSION OF PROTOTYPES DEVELOPED BY A TEAM.

The AT projects are typically client-oriented and follow the participatory action design principle. The involvement of the end-user in the product development process offers a more precise user requirement, particularly important in the case of AT that benefits a niche group. It also offers several learning benefits as a service learning component including increased personal and social development, improved academic skills and knowledge, and increased awareness and realistic view on career. ${ }^{1,44}$ In accordance with Eyler et al, $1999{ }^{45}$ findings, students in "well integrated service-learning courses were also more likely to apply subject matter knowledge to their problem analysis and to have well developed practical strategies for community action."

Multiple projects are chosen for each cohort to minimize team size to fewer than six members per team. The teams are mentored by faculty, other AT 'lead users' and graduate students who themselves have successfully completed the department's product realization courses and training.

\section{Curriculum Development/Summer Research Experience for Veterans}

Following the 12 week DBSL program, veterans and teachers split into different programs aligning closely with their respective end goals. The teachers continue with their experiential learning by participating in a four week summer workshop. The goal of this workshop is to develop a DBSL unit that would occupy 6-8 weeks of classroom time and direct students through the product development process leading to participation in the design competition. In the 


\section{International Journal for Service Learning in Engineering Special Edition, pp. 381-405, Fall 2014 \\ ISSN 1555-9033}

curriculum development workshop, teachers work as a team (comprising of teachers from the same school or teachers implementing the course together) developing or refining a DBSL unit through a combination of discussions and instruction. Teachers are provided with successfully developed units for biology, chemistry, and physics classrooms along with recent examples of DBSL units that they can adapt to their own classrooms. Apedoe et al, ${ }^{46}$ describes one such DBL curriculum developed at this workshop in the past (prior to current iteration of REVT that focuses on DBSL) and, its impact on the students along with guidelines for developing such curriculum. As a larger group teachers are instructed on pedagogical strategies that could help successfully implement a DBSL unit along with general information on inquiry-based learning and its application. Teachers use the tools and technology experienced in the REVT program, along with knowledge gained in the curriculum development workshop to guide their pedagogy and classroom activities.

The veterans continue through a ten week summer program entitled ELeVATE (Experiential Learning for Veterans in Assistive Technology and Engineering). This is a summer research experience program at the department that strives to provide military veterans with a translational research experience in engineering degree programs by exposing them to role models, experienced engineers as mentors, workshops, rehabilitation, vocational counseling and a writing seminar. Additionally, veterans are provided with support networks in our region and opportunities to meet other veteran mentors and peers. Veterans are paired with a research project and a mentor or group of mentors based on availability and interest, and are expected to work full-time through the program. Research projects are either independent or part of a larger project currently involving graduate and/or undergraduate students at HERL. ELeVATE forms an integral part of a larger design training initiative at HERL that includes REVT and REU. ${ }^{47}$

\section{Implementation of the DBSL unit and the Design Competition}

The veteran's component in the program ends with the ELeVATE program. The teachers however continue with the other phases of REVT, subsequently implementing the DBSL units in their classroom and entering their students into the design competition. Teachers are allowed to choose the time point in the curriculum at which they implement their units with the understanding that the students would complete their projects in time for the competition. Teachers receive ongoing support and guidance as they implement the units into their classrooms. The support includes help with classroom material purchase (each teacher receives a fixed budget for materials and other supporting item purchase for their classrooms), additional guidance on issues that stem from the implementation of the DBL unit through professional development sessions and classroom visits by the team, encouraging peer networking between the participating teachers to resolve other issues teachers may face and any assistance sort in identifying clients for their projects. The professional development sessions are typically three hour long and are conducted after school, focusing on addressing issues that arise in their classrooms, discussing additional strategies not covered during the curriculum development sessions and encouraging sharing of information between teachers.

The teachers then choose the grand challenge for their students, and direct teams of students towards achieving these goals. The schools are provided with additional support, if needed, to assist with the deployment of coursework along with 3D prototyping equipment to prototype student ideas. The participants' students work on a product design intended to be conducted as 


\section{International Journal for Service Learning in Engineering Special Edition, pp. 381-405, Fall 2014 \\ ISSN 1555-9033}

service learning with developing products for real clients (similar to the clients encountered by teachers in the REVT program), and culminating in a student design competition across the schools judged by a team chosen by the REVT program organizers.

\section{Design Competition for K-12 Students}

The design competition is conducted online, using specialized peer-evaluation software called SWoRD (Scaffolded Writing and Re-writing in Discipline). SWoRD has been successfully used in peer-evaluating language essays, and has been successfully implemented as a peer-design evaluation tool by our research team. ${ }^{48-50}$ In short, students peer-evaluate and filter the best twenty teams, which are then judged by a group of experts on SWoRD.

The expected outcome of each student team is a working prototype, with a poster and a video as the required submission artefacts. A rubric developed to evaluate the poster and video content is shared with the students beforehand helping them craft their submissions accordingly. Video content typically includes team describing their work along with features of their prototype. After an internal competition with their classrooms, the top one or two teams (depending on the class size) register on SWoRD and submit their artefacts. A randomization code assigns peers, from a different school, to evaluate each project using the same rubric provided to the students earlier. The feedback includes an objective score (4-point likert scale) and structured comments elicited by prompts. Each project receives upwards of five evaluations, with statistical corrections applied by SWoRD. Each team that receives feedback then back-evaluates the reviewer, in turn providing feedback to the reviewers. The score calculated by SWoRD is utilized to select the best twenty teams which are then judged by an expert group in SWoRD, with final deliberation over video conferencing to pick the top teams.

\section{Program Outcomes}

At the time of writing this article, one cohort of teachers and veterans has completed all aspects of the program, a second cohort is mid-way through the program, and a third cohort is beginning the program. Overall, 22 teachers and 9 veterans completed or are currently enrolled in the program since the inclusion of veterans was established. The teachers represented 6 schools with a cumulative class size of over 450 students. With each cohort, the program was iteratively developed based on periodic assessments. These assessments have also provided insight on participants' self-constructs as they progress through the program. The first cohort was part of the pilot implementation of the program with assessment methods being developed along with other organizational aspects of the program (conspicuous by their absence were the quantitative data from veterans owing to programmatic issues). The second cohort completed Phase I (DBSL) and Phase II (Curriculum Development for teachers/ELeVATE for veterans) earlier this year and is currently in the implementation part (Phase III; teachers only) of the program, once again missing the quantitative data for the veterans owing incomplete data from $2 / 2$ veterans. The third cohort is currently participating in Phase I. The assessment methodology described below is being currently implemented and for the sake of brevity focuses on the DBSL Unit. 


\section{Program assessment}

Participants are assessed at the beginning of the program and subsequently at the end of each phase of the program. For the design course, the assessment includes demographic information, information about teaching styles and participant opinion on STEM education (for teachers), completion of an Engineering Design Self-efficacy tool, and other open ended questions related to program goals and feedback. The assessment is carried out in the form of surveys (Appendix A). In addition to these surveys, participants are also recommended to maintain feedback journals that actively shape the pace and rigor of content delivered in class.

The engineering design self-efficacy tool was developed by Carberry et al, ${ }^{51}$ and designed to measure the individuals' self-concepts of engineering design tasks. Four task specific selfconcepts are evaluated: self-efficacy (confidence), motivation, success and anxiety. The tasks include nine items (as shown in figure 4) aligned with engineering design process. A Likert scale from 0-100 in 10 point increments is used to record participant response. The first item of the scale, "conduct engineering design" provides Engineering Design (ED) score for the individual, while the mean of the next eight items provides an Engineering Design Process (EDP) score for the individual.

\begin{tabular}{|c|c|c|c|c|c|c|c|c|c|}
\hline \multicolumn{10}{|c|}{$\begin{array}{l}\text { Rate your degree of (fill in task specific self-concept of interest) to perform the following tasks by recording a number from } 0 \text { to } 100 .(0=\text { low; } 50=\text { moderate; } \\
100=\text { high) }\end{array}$} \\
\hline & 10 & 20 & $\begin{array}{ll}0 & 30 \\
\end{array}$ & \begin{tabular}{|l|l|}
0 & 40 \\
\end{tabular} & 60 & 70 & 80 & 90 & 100 \\
\hline \begin{tabular}{|c|} 
conduct engineering design \\
\end{tabular} & & hginee & ring De. & sign (ED) Scort & & & & & \\
\hline \multicolumn{10}{|l|}{ identify a design need } \\
\hline \multicolumn{10}{|l|}{ research a design need } \\
\hline \multicolumn{10}{|l|}{ develop design solutions } \\
\hline select the best possible design & Engine & eering I & Design & Proces\$ (EDP) & Score & & & & \\
\hline \multicolumn{10}{|l|}{ construct a prototype } \\
\hline \multicolumn{10}{|l|}{ evaluate and test a design } \\
\hline \multicolumn{10}{|l|}{ communication a design } \\
\hline redesign & & & & & & & & & \\
\hline
\end{tabular}

FIGURE 4

\section{ENGINEERING DESIGN SELF-EFFICACY TOOL SHOWING THE NINE ITEMS THAT MEASURE A TASK} SPECIFIC SELF-CONCEPT

Using a pre- and post-design course assessment provided an opportunity to compare these scores and look at changes the participants underwent through the program. We posit that teachers' "will" in performing engineering design as measured by the tool, could indicate their potential to lead a successful implementation of DBL-units in schools. Assessing the spring 2014 cohort of teachers (4 math and 5 science teachers, 1 repeating math teacher from previous cohort) revealed that the confidence levels in conducting engineering design were significantly higher post-design course (Median $=80.00$ ) than pre-design course (Median $=60.00), \mathrm{z}=-2.205$ $\mathrm{r}<0.05 \mathrm{r}=0.735$. However, there were no significant differences measured for the other constructs (motivation, success and anxiety). Similarly, only the confidence levels in conducting the engineering design process were significantly higher post-design course $(\mathrm{M}=85.00)$ than predesign course $(M=60.14), t(8)=2.75 \mathrm{r}<0.05 \mathrm{r}=0.70$ while other constructs did not show any significant differences. Positive changes were noted for non-significant self-concepts from pre to 
post program, except for anxiety, where a negative trend was observed as is indicated in the figures 5 and 6 below.

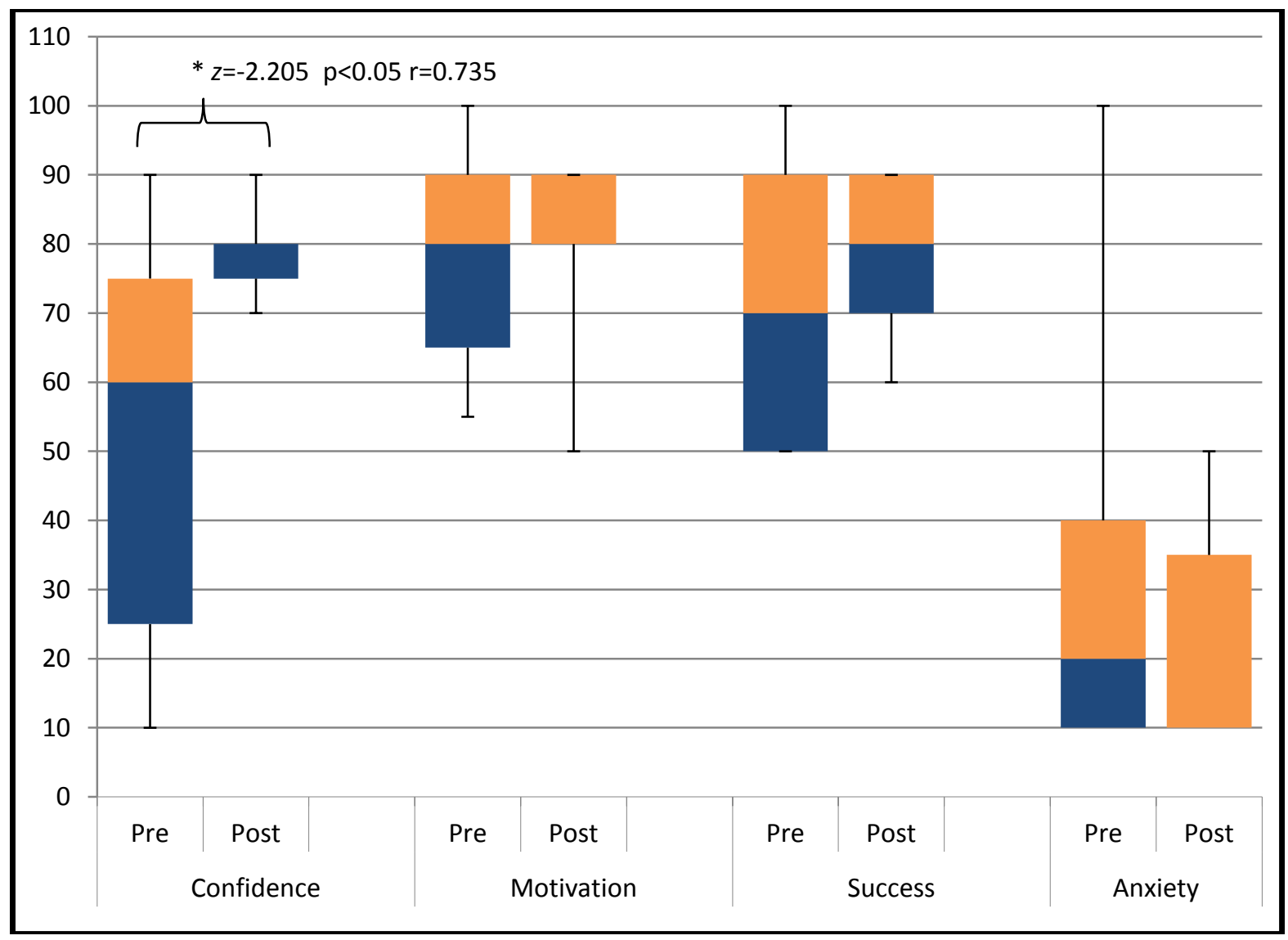

FIGURE 5

BOX PLOT SHOWING THE ENGINEERING DESIGN SCORES ON FOUR TASK SPECIFIC SELF CONCEPTS PRE AND POST PROGRAM. SIGNIFICANT CHANGES INDICATED BY P $<0.05$ AND MARKED BY AN * ON THE GRAPH. POSITIVE CHANGES WERE NOTED FOR NON-SIGNIFICANT SELF-CONCEPTS FROM PRE TO POST PROGRAM, EXCEPT FOR ANXIETY, WHERE A NEGATIVE TREND WAS OBSERVED 


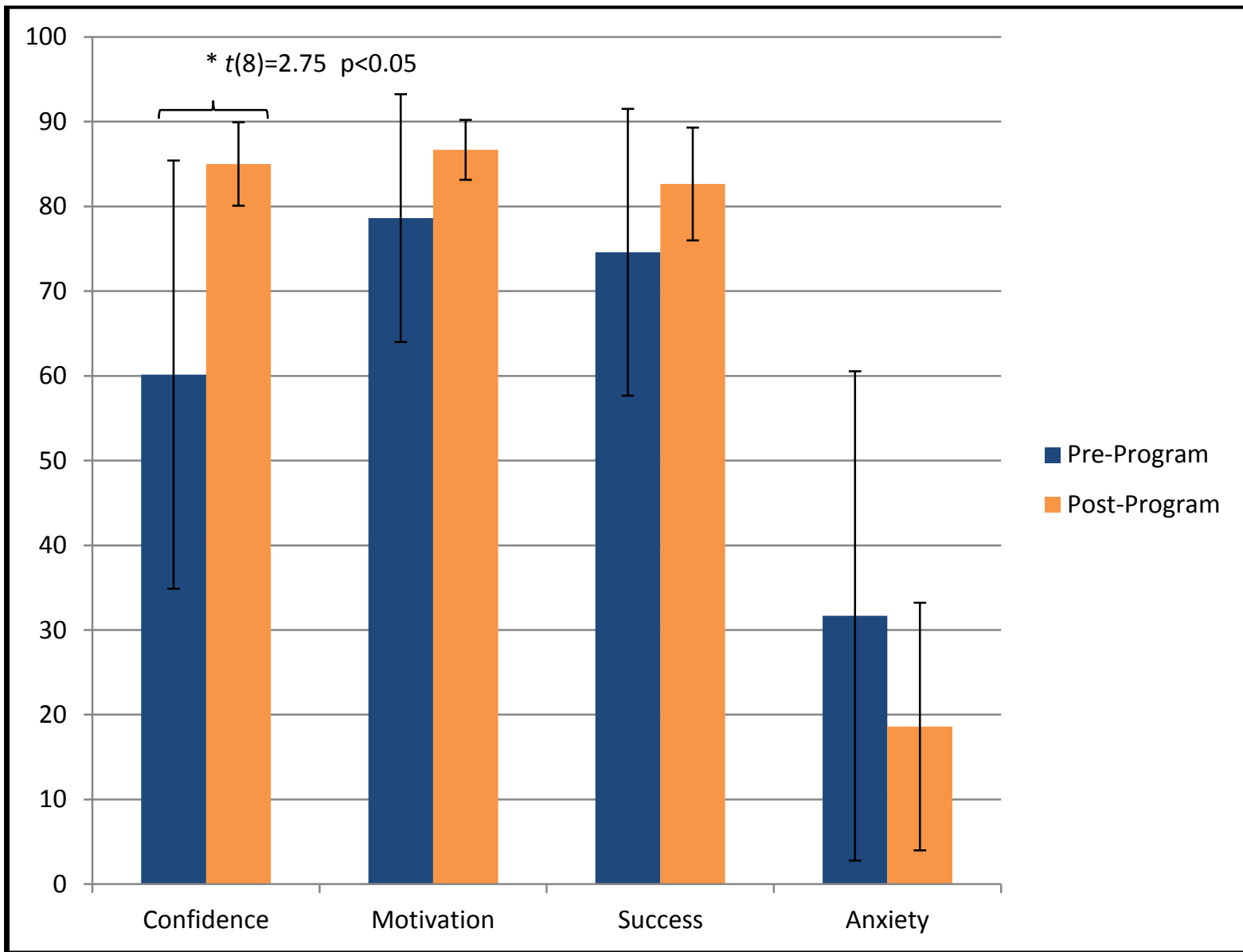

FIGURE 6

A BAR GRAPH SHOWING ENGINEERING DESIGN PROCESS SCORES FOR THE FOUR TASK SPECIFIC SELF CONCEPTS PRE AND POST PROGRAM. SIGNIFICANT CHANGES INDICATED BY P $<0.05$ AND MARKED BY AN * ON THE GRAPH. POSITIVE CHANGES WERE NOTED FOR NON-SIGNIFICANT SELF-CONCEPTS FROM PRE TO POST PROGRAM, EXCEPT FOR ANXIETY, WHERE A NEGATIVE TREND WAS OBSERVED

It should be noted that the sample size was quite small $(\mathrm{N}=10)$, consequently, the following interpretation should be examined within this context. Significant change in confidence levels show that the teachers felt more confident in conducting engineering design at the end of the program. Teachers entering the program were all motivated to perform engineering design (as suggested by their intention to undergo a $120 \mathrm{hr}$. design course commitment), and therefore the change noted in the motivations levels were not significantly different, although a trend was visible. Additionally, going through the whole design course could have been overwhelming to many, a significant departure from a closed-ended problem-solution space the teachers were familiar with, thereby making teachers more or less remain the same in terms of anxiety and anticipated success.

Qualitative data was collected from open ended questions. This data helped understand the teachers' perspective on inclusion of veterans (and vice-versa) and overall experience with the program. The program was rigorous and demanding, however, it gained popular acceptance by the participants, many of whom came to the course with no design or engineering experience. 
Although challenging at the beginning, the participants enjoy working in such an immersive environment and feel better equipped with the course knowledge by the end of the course. Examples of comments made were:

"The first few weeks were overwhelming, especially when the team was given our design challenge. No way could we correct the Hoyer transfer process for the client at least that is what I thought. In the end, we created 2 ways to improve the transfer process."

“. . . being a student again in unfamiliar territory [sic]. I had to learn the text, google docs, [and] team members, design process, etc., all at once. I was able to feel like a student again and faced with working through my learning curve. This is valuable for anyone to experience especially a teacher."

In both the examples above, the participants' confidence increased at the end, a valuable outcome that can help the teachers motivate their students in their project work. Similar outcome was noted in the case of the veteran students, noted in the paragraphs below.

All of the teacher participants from the first cohort re-applied to the program. However, in order to provide the REVT experience to teachers from diverse schools and other programmatic constraints, only one repeating teacher was included in the second cohort. Product design is an iterative process, similarly, learning the process sometimes requires multiple endeavors that are both practical and realistic. The teachers who participate in REVT are usually first time designers and unfamiliar with both design and engineering terms/methodology. And although the DBSL unit provides a good introduction to the subject and provides practical experience, it currently is the only such avenue for the teachers to gain expertise in the field in the region, and as such might explain the high percentage of participants interested in repeating the same program. This continued interest from the participants shows the value the teachers attributed to the experience. The following quotes demonstrate the impact REVT training has had on teacher participants and their pedagogy:

"When I took the REVT course the first time, we designed a pre-engineering course with a module in engineering design, 3D modeling, and statics \& structures... This year the pre-engineering course had 35 students and it was appropriately rigorous due to the preparation from the REVT . . For this coming school year, we are adding $3 D$ design and simulation. The enrollment for these three courses is over 225 students, which is about 25\% of our student body . . ."

“. . REVT provided an invaluable grounding in design philosophy and practices around working on an engineering team which were of great use to me in the course [that I teach]. I am noticing a difference already working with colleagues who don't have that shared experience to refer back to."

"I am thoroughly grateful to the REVT, as in teaching my class last year I was able to refer back to my experience extensively in preparing for class and in dealing with challenges that arose during the course of the class." 


\section{International Journal for Service Learning in Engineering \\ Special Edition, pp. 381-405, Fall 2014 \\ ISSN 1555-9033}

Similar interest was noted from the veteran student participants. They appreciated the opportunity to explore STEM without the additional pressure of grades and other academic requirements, as demonstrated in the anecdotes below.

"It's hard for transitioning military [vets] to decide to go back to school having been in such a structured system like the military. Many vets lack confidence in themselves to go outside of their comfort zone to explore possibilities in new careers... The REVT program is small yet informative enough to give vets a chance to explore these disciplines without failure. [Potential] for failure is a big factor for veterans when choosing to go to school instead of the workforce."

"REVT played a motivational role I would really like to have a job just like my experience in REVT. I was always changing and I feel it would always be fascinating."

The impact of REVT was also noticed on the participant teachers' students. At this stage of the program development, no direct assessment was performed on the K-12 students. This assessment will be included in this year's cohort and will be an element of future study; however, the quotes below demonstrate preliminary impactful findings.

"A significant number of the students in our Engineering Design course from last year have continued on into engineering-related studies at the university level. One student wrote back saying that she's enrolled in a freshman-level design course which has a similar design focus and she feels like she knows everything that they're trying to teach her. That level of authenticity is only reasonably due to the experience that ... and I had in the REVT, as we had nothing else significant to bring to the table."

"Fortunately, I am able to literally take the lessons from RETV directly into my engineering classroom. . . Since participating in the REVT, my students have learned about properly labeling their files, engaged in the iterative design process with authentic and meaningful work, collaborated and presented their projects to the whole class."

\section{LESSONS LEARNED}

As with any new program, the REVT is constantly undergoing refinement and revision. All stakeholders are considered when making these programmatic changes, while keeping the changes student-centered. The qualitative data plays a key role in helping make those decisions. Over the three iterations of the course, we have had successes in several aspects of the program at the same time several lessons learned, both of which will be detailed in the following section.

\section{Programmatic success:}

One of the biggest successes and a unique aspect of the program has been the integration of veterans into the program, creating both service and synergetic learning opportunities for both 
veterans and the teachers. The teachers who worked with veterans on their teams seemed to value the experience and leadership skills that the veterans bring with them. Logistically, the teachers also found the veterans' schedule complementary to their own allowing for shared responsibilities through the course. The quotes below reflect the teachers experience with veterans.

"The veterans provide a unique perspective on the design process. They've worked in the field and have more than textbook knowledge."

"Additionally, it was simply appreciated to have members with experiences and approaches that differ from a teaching perspective."

"The veterans that we worked with had different experiences and had hands on practical knowledge. Also, veterans were good with working with their hands and helped greatly in prototyping."

In addition to the programmatic convenience, the veterans found the program helpful in providing opportunities for networking and refining their goals, as suggested below.

"I learned more about the opportunities that are out there about design schools and grad schools that offer programs similar to the one we went through. Learning this helped me refine my choices in picking a career path."

"It was the first program I did as a Veteran and opened many doors for me as far as networking goes. It also led to a follow on internship."

Another success of the program has been the use of the flipped classroom which has helped use class time more effectively. Teachers and veterans found it helpful to be able to watch the lecture videos at their own pace and revisit content when needed anytime. This approach also helped the mentors and the instructors (authors) with opportunities to scaffold and provide additional feedback for the projects.

"I liked the setup of the program. The course work was guided enough to allow for success. The previous RET I attended left the engineering process more on the participants."

"I enjoyed this structure of the class. The resources used were exceptional!"

Furthermore, the clients were encouraged to participate in the team and play the role of mentor as well. They were added to the group collaborations tools, and participated in the team meetings, providing feedback and critique to the teams. The clients were enthusiastic about participation and thoroughly enjoyed the process. The quote below is from a client who worked with second cohort. 
"It was a great experience being able to share a need with a group of people learning the design process and being able to help them through the process."

To provide an inclusive experience to all participants, a rotating-leadership approach was used in the program. Each week, a new leader was elected by the team until a time where everyone had an opportunity to be a leader. Following which the team chose one for the rest of the course.

"I definitely have gained some valuable insight into time management and team management over this course. Given that we are aiming to run a variation of this course ourselves over the next academic year, getting some insight into what challenges my students might face has been very valuable in thinking about how to address them, both in structuring our course and in planning for whatever troubles eventually bubble up."

This rotating-leaders approach was aimed to provide each participant with an experience of leading and managing the team, subsequently introspecting and better understanding the issues that are presented when leading a diverse group of people. It also provided a way to create accountability in a no-credit program with little in the form of penalty for non-performing participants.

"The rotating role of team leader... [is] positive because everyone needs to be contributing and I think in the back of everyone's mind is the knowledge that their turn is coming up and that they will need the other team members to support them."

\section{Programmatic Challenges:}

Over the three cohorts who have completed or are currently completing the program, a notable issue observed by the program coordinators has been participants' familiarity with technology. The constraint of in-service teachers and student veterans that includes time and colocation, combined with the once per week class completed within a short 12 weeks, necessitates the use of collaborative technology. This collaboration beyond the class is recommended by the instructors and encouraged through the use of free online services. It has been observed that the participants required approximately three to four weeks to get comfortable using these services, eating up class time and adding to participants' workload. A potential solution being tested is the use of additional video exercises that focuses on use of technology and partnering with K-12 institutions to encourage IT administrators assist the teachers with required software needs.

Aligning the REVT program schedule along with the in-service teachers schedule has been another difficulty, although not observed with the veteran participants. The two part program followed a spring - summer approach as mentioned above, with the classroom implementation in the following fall. It was noted through the program that the teachers wanted time to reflect between the program milestones and the current set up was quite constrained on time to allow for such. 
"I think that more teachers would participate if the design portion of the class were offered in the fall and the curriculum writing in the spring . . . Those summer months are really a time to mentally unwind and re-charge."

A new schedule is being tested with the current cohort, with the design course now being offered in fall and the curriculum component in the spring. Other aspects of the program remain the same. Veterans on the other hand would enter the ELeVATE program in the summer in the following year after the fall design course. The impact of this schedule will be evident as we complete the planned assessments for this cohort.

Another area for improvement in the program is the development of assessment tools to measure the impact of the program on the K-12 students and the long term effects on the teachers' pedagogy. Specifically, whether student outcomes match the outcomes we observed in the DBSL unit with teachers, and whether the DBSL unit in K-12 school remains sustainable over a period of time since participation in the program?

\section{CONCLUSION}

REVT is a successful service learning intervention in that it brings two diverse populations together in a single training program; both veterans and teachers find the program beneficial, develop an increased understanding of the engineering process and gain confidence in their abilities to perform engineering design. Veterans, through their military experiences, provide an additional dimension to the experiential learning provided to the teachers through the RET program. Veterans themselves benefit from the program and have shown an increased appreciation and interest in technology and engineering. The teachers benefited from the AT based projects and gained a better understanding of the disability community. In addition, the teachers had an increased understanding of the product design and development process and were able to implement the same in their K-12 classes. Overall, the program successfully engaged the target population in STEM related activities and helped them towards their subsequent professional goals. The participants gained empathy for the clients, were motivated to work on the projects and felt accomplished at the end. It provided tangible benefit to the clients in the form of an AT device and a long term mentoring experience.

A more concentrated effort on the long-term effects of the program on the participants' career pathways is needed. REVT offers opportunities to study two varied population groups while better understanding their needs and identifying ways to improve their professional skills. The program provides additional resources to veterans transitioning to academia and unique experiences and values for the teachers that can be carried forward through to their students.

Future work includes implementing K-12 student assessment, to understand the impact REVT training had on their classroom experience and academic outcomes, and continued longterm assessment and tracking of all the participants from the program to further our comprehension. 


\section{ACKNOWLEDGMENT}

This project is supported by the grants: Connecting Research and Teaching through Product Innovation: QoLT RET site EEC1161880, Research Experience for Veterans/Teachers (supplement to the QoLT Engineering Research Center EEC0540865), and Veterans' Research Supplement EEC1360573.

The authors would like to thank Ms. Birdy Reynolds, Dr. Christian Schunn, Robbie Paolini, the clients, mentors, and program participants for their contributions to this project. The authors would also like to thank the Human Engineering Research Laboratories for use of their space and facilities to successfully complete the program.

The contents of this manuscript do not represent the views of the Department of Veterans Affairs, the United States Government or the National Science Foundation.

\section{REFERENCES}

1 Billig, Shelley H. "Research on K-12 School-Based Service-Learning." Phi Delta Kappan 81, no. 9 (2000): 658-64.

2 Weiler, Daniel, Amy LaGoy, Eric Crane, and Abby Rovner. "An Evaluation of K-12 ServiceLearning in California: Phase Ii Final Report." Emeryville, CA: RPP International no. (1998).

3 Follman, Joseph. "Florida Learn and Serve: 1996-97 Outcomes and Correlations with 1994-95 and 1995-96." Center for Civic Education and Service. Tallahassee, FL: Florida State University no. (1998).

4 Eyler, Janet, Dwight E. Giles, Jr., and John Braxton. "The Impact of Service-Learning on College Students." Michigan Journal of Community Service Learning 4, no. (1997): 5.

5 Lee, Hwa, and Rosalyn Templeton. "Ensuring Equal Access to Technology: Providing Assistive Technology for Students with Disabilities." Theory Into Practice 47, no. 3 (2008): 212-19.

6 Stumbo, Norma J., Jay K. Martin, and Brad N. Hedrick. "Assistive Technology: Impact on Education, Employment, and Independence of Individuals with Physical Disabilities." Journal of Vocational Rehabilitation 30, no. 2 (2009): 99-110.

7 Martin, Jeffrey J. "Benefits and Barriers to Physical Activity for Individuals with Disabilities: A Social-Relational Model of Disability Perspective." Disability \& Rehabilitation 35, no. 24 (2013): 2030-37.

8 Hedrick, Brad, TL Pape, Allen W Heinemann, Jennifer L Ruddell, and Janet Reis. "Employment Issues and Assistive Technology Use for Persons with Spinal Cord Injury." Journal of rehabilitation research and development 43, no. 2 (2006): 185.

9 Alper, Sandra, and Sahoby Raharinirina. "Assistive Technology for Individuals with Disabilities: A Review and Synthesis of the Literature." Journal of Special Education Technology 21, no. 2 (2006): 47.

10 Terpenny, Janis P, Richard M Goff, Mitzi R Vernon, and William R Green. "Utilizing Assistive Technology Design Projects and Interdisciplinary Teams to Foster Inquiry and Learning in Engineering Design." International Journal of Engineering Education 22, no. 3 (2007): 609.

11 Russell, Susan H, and Mary P Hancock. "Evaluation of the Research Experiences for Teachers (Ret) Program: 2001-2006." NSF Contract Number EEC-9815426. SRI International. Menlo Park, $C A$ no. (2007).

12 The National Science Foundation. "Research Experiences for Teachers (Ret) in Engineering and Computer Science." Directorate for Engineering, Directorate for Computer \& Information Science \& Engineering, NSF 11-509, [Accessed Sept, 2014]. http://www.nsf.gov/funding/pgm_summ.jsp?pims_id=5736. 


\section{International Journal for Service Learning in Engineering Special Edition, pp. 381-405, Fall 2014 \\ ISSN 1555-9033}

13 Buxner, Sanlyn Rebecca. 2010. "Exploring the Impact of Science Research Experiences for Teachers: Stories of Growth and Identity."Dissertation, The University of Arizona.

14 Tobias, Sheila, and Anne Baffert. Science Teaching as a Profession: Why It Isn't, How It Could $B e$. Arlington, VA: NSTA Press, National Science Teachers Association,2010.

15 Mouza, Chrystalla. "Does Research-Based Professional Development Make a Difference? A Longitudinal Investigation of Teacher Learning in Technology Integration." The Teachers College Record 111, no. 5 (2009): 1195-241.

16 National Science Board. "America's Pressing Challenge — Building a Stronger Foundation." National Science Foundation, NSB 06-02, [Accessed April, 2014]. http://www.nsf.gov/statistics/nsb0602/.

17 Venezia, Andrea, and Michael W Kirst. "Inequitable Opportunities: How Current Education Systems and Policies Undermine the Chances for Student Persistence and Success in College." Educational Policy 19, no. 2 (2005): 283-307.

18 Maple, Sue A, and Frances K Stage. "Influences on the Choice of Math/Science Major by Gender and Ethnicity." American Educational Research Journal 28, no. 1 (1991): 37-60.

19 Rask, Kevin. "Attrition in Stem Fields at a Liberal Arts College: The Importance of Grades and Pre-Collegiate Preferences." Economics of Education Review 29, no. 6 (2010): 892-900.

20 Besterfield-Sacre, Mary, Cynthia J. Atman, and Larry J. Shuman. "Characteristics of Freshman Engineering Students: Models for Determining Student Attrition in Engineering." Journal of Engineering Education 86, no. 2 (1997): 139-49.

21 Minner, Daphne D., Abigail Jurist Levy, and Jeanne Century. "Inquiry-Based Science Instruction-What Is It and Does It Matter? Results from a Research Synthesis Years 1984 to 2002." Journal of Research in Science Teaching 47, no. 4 (2010): 474-96.

22 National Research Council. National Science Education Standards. Washington, D.C.: National Academy Press, 1996.

23 Schwartz, Reneé S, Norman G Lederman, and Barbara A Crawford. "Developing Views of Nature of Science in an Authentic Context: An Explicit Approach to Bridging the Gap between Nature of Science and Scientific Inquiry." Science education 88, no. 4 (2004): 610-45.

24 Hakanen, Jari J, Arnold B Bakker, and Wilmar B Schaufeli. "Burnout and Work Engagement among Teachers." Journal of school psychology 43, no. 6 (2006): 495-513.

25 Maslach, Christina, Wilmar B Schaufeli, and Michael P Leiter. "Job Burnout." Annual review of psychology 52, no. 1 (2001): 397-422.

26 Maslach, Christina. "Burnout." Human behavior 5, no. 9 (1976): 16-22.

27 Strage, Amy. "Long-Term Academic Benefits of Service-Learning: When and Where Do They Manifest Themselves?" College Student Journal 38, no. 2 (2004): 257.

28 Bell, Randy L, Lara Smetana, and Ian Binns. "Simplifying Inquiry Instruction." The Science Teacher 72, no. 7 (2005): 30-33.

29 Windschitl, Mark. "Folk Theories of "Inquiry:" How Preservice Teachers Reproduce the Discourse and Practices of an Atheoretical Scientific Method." Journal of Research in Science Teaching 41, no. 5 (2004): 481-512.

30 Abd-El-Khalick, Fouad, Saouma BouJaoude, Richard Duschl, Norman G. Lederman, Rachel Mamlok-Naaman, Avi Hofstein, Mansoor Niaz, David Treagust, and Hsiao-lin Tuan. "Inquiry in Science Education: International Perspectives." Science Education 88, no. 3 (2004): 397-419.

31 Capps, DanielK, and BarbaraA Crawford. "Inquiry-Based Instruction and Teaching About Nature of Science: Are They Happening?" Journal of Science Teacher Education 24, no. 3 (2013): 497526.

32 Barrow, Lloyd H. "A Brief History of Inquiry: From Dewey to Standards." Journal of Science Teacher Education 17, no. 3 (2006): 265-78.

33 Ackerman, Robert, David DiRamio, and Regina L Garza Mitchell. "Transitions: Combat Veterans as College Students." New Directions for Student Services 2009, no. 126 (2009): 5-14. 


\section{International Journal for Service Learning in Engineering Special Edition, pp. 381-405, Fall 2014 \\ ISSN 1555-9033}

34 DiRamio, David, Robert Ackerman, and Regina L Mitchell. "From Combat to Campus: Voices of Student-Veterans." NASPA Journal 45, no. 1 (2008): 73-102.

35 Bauman, Mark C. Called to Serve: The Military Mobilization of Undergraduates: ERIC. Dissertation,2009.

36 Franek, Robert, Tom Meltzer, and Christopher Maier. The Best 368 Colleges 2009. Vol. 368 : Random House LLC,2008.

37 CNA. 2007. Population Representation in the Military Services Fiscal Year 2007. Alexandria, VA: Office of the Under Secretary of Defense, Personnel and Readiness.

38 American Council on Education. "Ace Launches Online Toolkit for Institutions Serving Veterans." [Accessed Jan 24, 2014]. http://www.acenet.edu/news-room/Pages/Launches-Toolkit-Veterans.aspx.

39 National Science Foundation. "Dear Colleague Letter: Veteran's Research Supplement (Vrs) Program." NSF 13-047, [Accessed Oct, 2014]. http://www.nsf.gov/pubs/2014/nsf14124/nsf14124.jsp.

40 Doppelt, Yaron, Christian D Schunn, Eli M Silk, Matthew M Mehalik, Birdy Reynolds, and Erin Ward. "Evaluating the Impact of a Facilitated Learning Community Approach to Professional Development on Teacher Practice and Student Achievement." Research in Science \& Technological Education 27, no. 3 (2009): 339-54.

41 Burns, Martha, Keith Storey, and Nicholas J Certo. "Effect of Service Learning on Attitudes Towards Students with Severe Disabilities." Education and Training in Mental Retardation and Developmental Disabilities 34, no. 1 (1999): 58-65.

42 Lieberman, Lauren J, Cathy Houston-Wilson, and Francis M Kozub. "Perceived Barriers to Including Students with Visual Impairments in General Physical Education." Adapted Physical Activity Quarterly no. (2002).

43 Hand, Karen, Lauren Lieberman, and Moira Stuart. "Beliefs About Physical Activity among Children Who Are Visually Impaired and Their Parents." Journal of Visual Impairment \& Blindness (JVIB) no. 04 (2006).

44 Eyler, Janet, Dwight E Giles Jr, Christine M Stenson, and Charlene J Gray. At a Glance: What We Know About the Effects of Service-Learning on College Students, Faculty, Institutions and Communities, 1993-2000: Vanderbilt University Nashville, TN,2001.

45 Eyler, Janet, and Dwight E Giles Jr. Where's the Learning in Service-Learning? Jossey-Bass Higher and Adult Education Series: ERIC,1999.

46 Apedoe, Xornam S, Birdy Reynolds, Michelle R Ellefson, and Christian D Schunn. "Bringing Engineering Design into High School Science Classrooms: The Heating/Cooling Unit." Journal of Science Education and Technology 17, no. 5 (2008): 454-65.

47 Goldberg, Mary, Jon Pearlman, and Mahender Mandala. 2013. "An Innovative Approach to Design Education across the Academic Pipeline: Technology Innovations for People with Disabilities." ASME 2013 International Design Engineering Technical Conferences and Computers and Information in Engineering Conference.

48 Cho, Kwangsu, and Christian Schunn. 2003. "Battling the Tyranny of the Thousands with a Sword: Scaffolded Writing and Rewriting in the Discipline." World Conference on Educational Multimedia, Hypermedia and Telecommunications.

49 Cho, Kwangsu, and Christian D Schunn. "Scaffolded Writing and Rewriting in the Discipline: A Web-Based Reciprocal Peer Review System." Computers \& Education 48, no. 3 (2007): 409-26.

50 Cho, Kwangsu, and Christian D Schunn. 2004. "The Sword Is Mightier Than the Pen: Scaffolded Writing and Rewriting in the Discipline." Advanced Learning Technologies, 2004. Proceedings. IEEE International Conference on.

51 Carberry, Adam R., Hee-Sun Lee, and Matthew W. Ohland. "Measuring Engineering Design Self-Efficacy." Journal of Engineering Education 99, no. 1 (2010): 71-79. 


\section{Appendix A}

Pre-DBSL unit survey excerpt (showing few relevant questions for the sake of brevity):

Section 1: Name and Demographics

Section 2: STEM Background

$\mathrm{Q}$ - Please describe any academic and/or professional engineering/product design experiences. Please detail your involvement in terms of position, time involved, etc. [Open ended]

Section 3: Type of user - 'lead user' or ordinary user

The following questions will help us identify the type of user you are of devices available in the market.

Q - Have modified a product or, designed and fabricated my own version of a consumer product to meet my expected performance characteristics?

Always/Usually/About half the time/Seldom/Never

Comment (optional)

Q - Have used a commercially available product, either modified or unmodified, in a field or purpose different from its intended typical use.

Always/Very often/Sometimes/Rarely/Never

Comment (optional)

Q - Routinely find commercially available products unable to satisfy my specific needs; or have difficulty finding a product with characteristics I desire.

Always/Very often/Sometimes/Rarely/Never

Comment (optional)

Section 4: Teaching Experience (only for teachers)

Section 5: Pre-program Design Thinking

Q - Please respond to the following set of statements relating to your current thinking about engineering. (Strongly/Disagree/Disagree/Neutral/Agree/Strongly Agree)

- I am aware of what engineers do

- I believe that engineering has a large impact on my daily life

- I believe that engineering is an important career

- I believe that only a few of the students I teach could succeed as an engineer

- I think that engineering can be used to teach core science ideas

- I believe that science is not for everyone

- I think that engineering can be used to teach core math ideas

- I believe that math is not for everyone

- I believe that engineering is a difficult discipline

- I believe engineering is a "helping profession"

$\mathrm{Q}$ - Please respond to the following set of statements relating to your current thinking about design. (Strongly/Disagree/Disagree/Neutral/Agree/Strongly Agree)

- I believe I have the necessary skills to design a product 
- On a design team, I know my role and how I can best contribute

- I consider myself to be a creative innovator

- I am confident in my design skills

- I am comfortable working with clients

- I am confident in analyzing complex problems

- I am confident in my ability to prototype a product

- I am confident in my ability to perform materials testing

- I am knowledgable of the product development process

- I am knowledgable of the technology transfer process (transferring a product to the market)

- I am knowledgable of commercially available assistive technologies

Q - I believe that the type of students that can do engineering design include one or all of the following (Teachers Only)

Students cannot do engineering design/Students strong in math and science/Students who are creative/Students who are motivated to learn/All students can do engineering design

Comment (optional)

Section 6: Design Self-efficacy

Q - Rate your degree of confidence (i.e. belief in your current ability) to perform the following tasks by recording a number from 0 to 100 . $(0=$ cannot do at all; $50=$ moderately can do; $100=$ highly certain can do)

- conduct engineering design

- identify a design need

- research a design need

- develop design solutions

- $\quad$ select the best possible design

- construct a prototype

- evaluate and test a design

- communicate a design/redesign

Q - Rate how motivated you would be to perform the following tasks by recording a number from 0 to 100 . $(0=$ not motivated; $50=$ moderately motivated; $100=$ highly motivated $)$

- conduct engineering design

- identify a design need

- research a design need

- develop design solutions

- $\quad$ select the best possible design

- construct a prototype

- evaluate and test a design

- communicate a design/redesign

$\mathrm{Q}$ - Rate how successful you would be in performing the following tasks by recording a number from 0 to 100 . ( $0=$ cannot expect success at all; 50=moderately expect success; $100=$ highly certain of success)

- conduct engineering design

- identify a design need 
- research a design need

- develop design solutions

- select the best possible design

- construct a prototype

- evaluate and test a design

- communicate a design/redesign Q - Rate your degree of anxiety (how apprehensive you would be) in performing the following tasks by recording a number from 0 to 100 . $(0=$ not anxious at all; $50=$ moderately anxious; $100=$ highly anxious)

- conduct engineering design

- identify a design need

- research a design need

- develop design solutions

- select the best possible design

- construct a prototype

- evaluate and test a design

- communicate a design/redesign

Section 7: Open ended questions (Teachers only)

Q - Please use the space below to comment on the kinds of strategies that best support your learning of new content or ideas.

$\mathrm{Q}$ - Please share 3 (or more) goals for your RET experience.

$\mathrm{Q}$ - Please share 3 (or more) expectations for the design course portion of the RET experience.

$\mathrm{Q}$ - Please share an area(s) of your teaching practice that you would like to improve.

$\mathrm{Q}$ - What do you think will be the most important impact that your participation in the RET program have on your students or your school/school system?

Section 8: Open ended questions (Veterans only)

$\mathrm{Q}$ - Please share your goals for

Short-term career goals/Long-term career goals/REVT program goals

$\mathrm{Q}$ - Based on your goals, what obstacles do you foresee?

$\mathrm{Q}$ - What do you think will be the most important impact, if any, that your participation in the REVT program have on you and your career goals?

Post-DBSL unit survey excerpt: The post-DBSL survey mimics the pre-survey with the exception of change of tense for the open-ended questions. 